\title{
JC Viral Infection-Related Cerebellar Degeneration as the First Manifestation of AIDS
}

\author{
Hae-Won Shin Suk Y. Kang Young H. Sohn \\ Department of Neurology and Brain Research Institute, Brain Korea 21 Project for Medical Science, \\ Yonsei University College of Medicine, Seoul, South Korea
}

\begin{abstract}
Dear Sir,
Primary cerebellar degeneration is rarely associated with human immunodeficiency virus type 1 (HIV) infection [1]. Since the cerebellum is not immune to the ravages of HIV infection [1], its underlying mechanism is still obscure. Recently, the human polyomavirus JC (JCV), a wellknown causative agent of progressive multifocal leukoencephalopathy (PML) in immunosuppressed individuals, was reported to produce granule cell damage in a patient with acquired immune deficiency syndrome (AIDS) [2, 3]. Here, we introduce a patient with AIDS who presented with subacute onset of progressive cerebellar degeneration and central nervous system (CNS) infection with JCV.
\end{abstract}

\section{Case Report}

A 37-year-old woman presented with a progressively unsteady gait and dizziness, which had developed 9 months earlier. Her medical history was significant for allergic dermatitis for 3 years but not for any infectious illness or alcohol/drug abuse. Two months earlier, the patient had undergone a brain MRI because of the above symptoms, which had been normal at that time (fig. 1A). Examination revealed slurred speech, severe ataxic gait and symmetric limb ataxia in the upper and lower extremities. The rest of the neurological examination was normal. The patient demon- strated intact cognitive function. A repeat brain MRI showed remarkable cerebellar atrophy without any supratentorial or white matter lesions (fig. 1B). Routine serologic tests including serum vitamin B12 level, folate level and liver enzymes were normal. Cerebrospinal fluid (CSF) analysis was unremarkable. Genetic studies for spinocerebellar ataxia (types 1, 2, 3, 6 and 7) and Friedreich ataxia were negative. Paraneoplastic markers including anti$\mathrm{Hu}$, anti-Yo and anti-Purkinje-cell antibodies were also negative. CSF revealed no antibodies for cytomegalovirus, herpes simplex, varicella-zoster or Toxoplasma gondii. Anti-HIV antibody and HIV antigen were positive in both serum and CSF. This was later confirmed by Western blot testing. The absolute CD4+ lymphocyte count was $1 \mathrm{cell} / \mathrm{mm}^{3}, 205 \mathrm{CD} 8+$ cells/ $\mathrm{mm}^{3}$, and the plasma HIV viral load was 410,000 copies/ml. One month after admission, JC viral DNA was detected in CSF by polymerase chain reaction.

A highly active antiretroviral treatment (HAART) regimen, composed of zidovudine, lamivudine, lopinavir and ritonavir, was initiated and maintained. The HIV viral load was significantly reduced to 25 copies $/ \mathrm{ml}$ at 3 months, and less than 25 copies/ml at 6 months after treatment. The absolute CD4+ and CD8+ lymphocyte counts were increased to 35 and 1,305 cells $/ \mathrm{mm}^{3}$ at 3 months, and 57 and 962 cells $/ \mathrm{mm}^{3}$ at 6 months after HAART, re- spectively. After detection of JC viral DNA in CSF, cidofovir, an experimental therapeutic agent for JCV [4], was administered intravenously and repeated for a total of 10 cycles. The patient's ataxia improved partially after treatment and was stable until 1 year later. However, her symptoms were eventually progressed so that she was unable to stand and had difficulty sitting on a chair after a 30-month follow-up, although she did not show cognitive dysfunction.

\section{Discussion}

At the initial presentation, we explored known possible causes of primary cerebellar degeneration including a history of alcohol and drug abuse, genetic studies for hereditary ataxia, paraneoplastic markers and viral antibodies for possible CNS infections, all of which were negative. Therefore, positive test results for HIV infection led us to infer that the subacute cerebellar degeneration in this patient was associated with HIV infection. Although ataxia and cerebellar atrophy are not uncommon in the patients with HIV dementia [5, 6], pure cerebellar degeneration associated with HIV infection in the absence of other neurological complication has rarely been reported $[1-3,7-10]$. This patient may represent an additional case illustrating such association.

\section{KARGER \\ Fax +41 613061234 \\ E-Mail karger@karger.ch}

www.karger.com
(C) 2008 S. Karger AG, Basel

0014-3022/08/0594-0205\$24.50/0

Accessible online at:

www.karger.com/ene
Young H. Sohn, MD

Department of Neurology, Yonsei University College of Medicine

134 Shinchon-dong, Seodaemun-gu

Seoul, 120-752 (South Korea)

Tel. +82 2228 1608, Fax +82 2393 0705, E-Mail yhsohn62@yumc.yonsei.ac.kr 

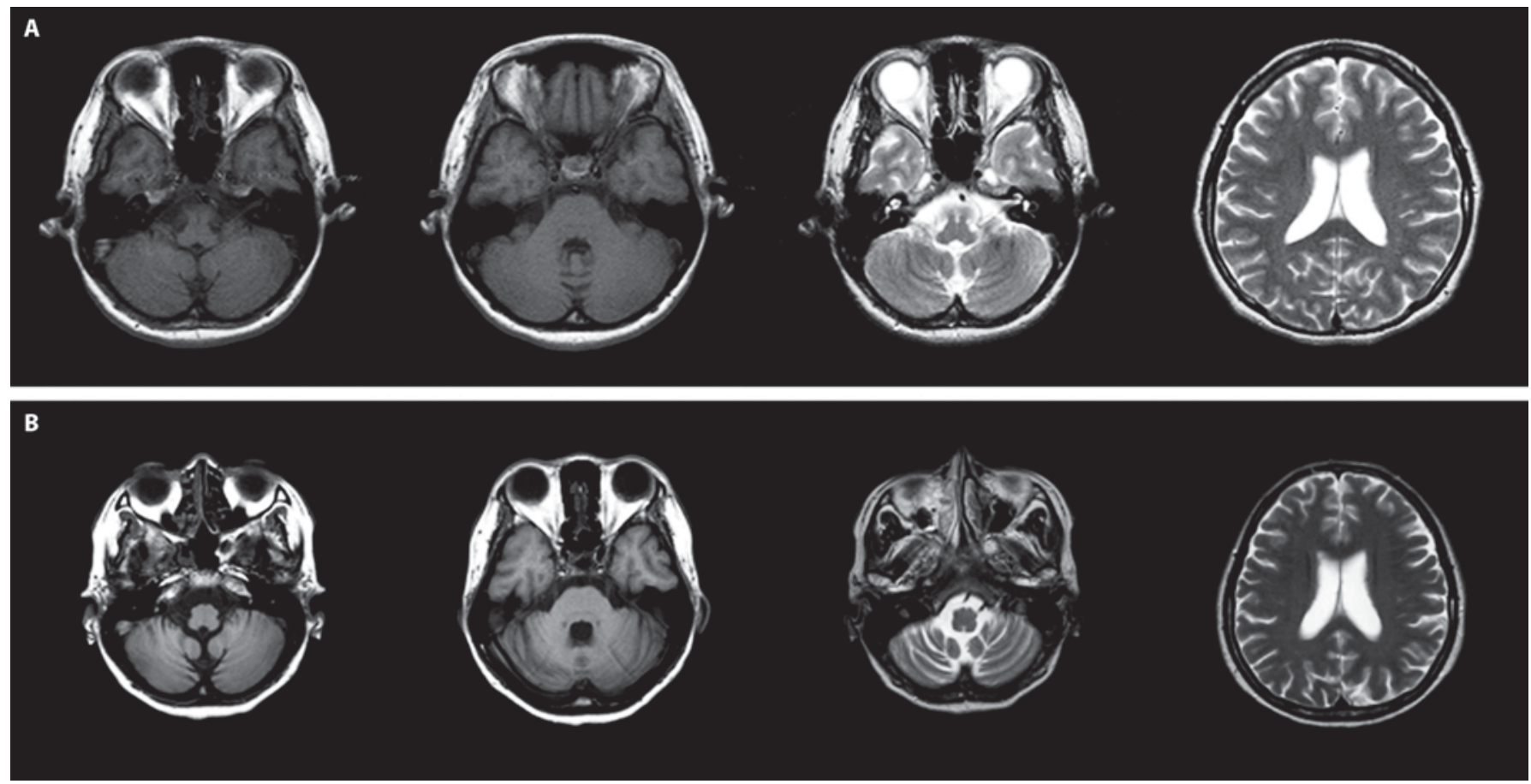

Fig. 1. A Initial MRI of $\mathrm{T}_{1^{-}}$and $\mathrm{T}_{2}$-weighted axial sections. There are no cerebellar or white matter lesions. B Repeat MRI performed 2 months later. Compared to the initial imaging, there is prominent atrophy of the cerebellum but no lesions in the cerebellar or periventricular white matter.

Brain MRI often discloses prominent cerebellar atrophy and sometimes may identify asymptomatic white matter lesions or cerebral atrophy $[1,2,7,8]$. Neuropathology demonstrated that the cerebellar atrophy in these patients resulted mainly from scattered destruction of the granule cell layer [1-3]. Recently, it has been discovered that the JCV infection causes the cerebellar granule cell damage, distinct from PML, in patients with HIV $[2,3]$. Detection of viral DNA in CSF has a highly positive predictive value for JCV infection in the brain, which could sufficiently replace confirmation based on pathology in the patients with PML [11]. Although the presence of JCV infection was not confirmed by tissue pathology, detection of JC viral DNA in CSF in this patient may indicate a probability of CNS infection with JCV. Since this patient did not show any white matter lesions consistent with PML on brain MRI, JCV infection in this case is presumably confined to the cerebellum as demonstrated by Koralnik et al. [3].
Prognosis of HIV-related cerebellar degeneration is usually poor, although only limited information is currently available for its long-term clinical course. As cerebellar atrophy progresses, ataxia often worsens, eventually leaving patients entirely dependent [1,2,7-10]. Some patients' conditions were complicated by other neurological deficits such as dementia, and they died within a few years of ataxia onset $[1,2,7,8]$. Only 1 patient reported by Koralnik et al. [3] showed symptomatic improvement and stable clinical course during an 8-year follow-up with HAART and cidofovir treatment. Our patient also showed partial and transient improvement after HAART and cidofovir treatment but eventually progressed to leave the patient totally dependent at 3 years after symptom onset. Although the patient's neurological deficits were improved temporarily after cidofovir administration in addition to HAART, it seems uncertain whether cidofovir could contribute this temporary improvement in addition to the effect of HAART itself, considering the results of previous studies $[4,12]$. The pres- ent case provides additional support for an involvement of JCV in pure cerebellar dysfunction in AIDS patients. Thus, in HIVinfected patients with otherwise unexplained cerebellar syndrome, a concomitant JCV infection should systematically be looked for.

\section{References}

1 Tagliati M, Simpson D, Morgello S, Clifford D, Schwartz RL, Berger JR: Cerebellar degeneration associated with human immunodeficiency virus infection. Neurology 1998; 50:244-251.

2 Du Pasquier RA, Corey S, Margolin DH, Williams K, Pfister LA, De Girolami U, Mac Key JJ, Wuthrich C, Joseph JT, Koralnik IJ: Productive infection of cerebellar granule cell neurons by JC virus in an HIV+ individual. Neurology 2003;61:775-782.

3 Koralnik IJ, Wuthrich C, Dang X, Rottnek M, Gurtman A, Simpson D, Morgello S: JC virus granule cell neuronopathy: a novel clinical syndrome distinct from progressive multifocal leukoencephalopathy. Ann Neurol 2005;57:576-580. 
4 Marra CM, Rajicic N, Barker DE, Cohen BA, Clifford D, Donovan Post MJ, Ruiz A, Bowen BC, Huang ML, Queen-Baker J, Andersen J, Kelly S, Shriver S: A pilot study of cidofovir for progressive multifocal leukoencephalopathy in AIDS. AIDS 2002;16:1791-1797.

5 Navia BA, Jordan BD, Price RW: The AIDS dementia complex. I. Clinical features. Ann Neurol 1986;19:517-524.

6 Flowers CH, Mafee MF, Crowell R, Raofi B, Arnold P, Dobben G, Wycliffe N: Encephalopathy in AIDS patients: evaluation with MR imaging. AJNR Am J Neuroradiol 1990; 11:1235-1245.
7 Yebra M, Garcia-Merino A, Albarran F, Varela JM, Echevarria JM: Cerebellar disease without dementia and infection with the human immunodeficiency virus (HIV). Ann Intern Med 1988;108:310-311.

8 Graus F, Ribalta T, Abos J, Alom J, Cruz-Sanchez F, Mallolas J, Miro JM, Cardesa A, Tolosa E: Subacute cerebellar syndrome as the first manifestation of AIDS dementia complex. Acta Neurol Scand 1990;81:118-120.

9 Kwakwa HA, Ghobrial MW: Primary cerebellar degeneration and HIV. Arch Intern Med 2001;161:1555-1556.

10 Puertas I, Jimenez-Jimenez FJ, Gomez-Escalonilla C, Sayed Y, Cabrera-Valdivia F, Rojas R, Sanz-Moreno J: Progressive cerebellar syndrome as the first manifestation of HIV infection. Eur Neurol 2003;50:120-121.
11 McGuire D, Barhite S, Hollander H, Miles M: JC virus DNA in cerebrospinal fluid of human immunodeficiency virus-infected patients: predictive value for progressive multifocal leukoencephalopathy. Ann Neurol 1995;37:395-399.

12 Gasnault J, Kousignian P, Kahraman M, Rahoiljaon J, Matheron S, Delfraissy JF, Taoufik Y: Cidofovir in AIDS-associated progressive multifocal leukoencephalopathy: a monocenter observational study with clinical and JC virus load monitoring. J Neurovirol 2001;7:375-381. 